\title{
Knowledge, attitude, practices and their associated factors towards HIV/AIDS among residents of Benadir Region, Somalia
}

\author{
Hassan Abdullahi Dahie \\ Faculty of Health Science, Mustaqbal University, \\ Mogadishu-Somalia \& SOS Community Nursing School, Mogadishu-Somalia.
}

\author{
Abdullahi Ali Heyle \\ SOS Community Nursing School, Mogadishu-Somalia
}

\begin{abstract}
Background: HIV/AIDS is a global challenge that has threatened the very existence of the human race. There were approximately 36.7 million people worldwide living with HIV/AIDS at the end of 2016 of whom an estimated 1.8 million individuals worldwide became newly infected with in the year 2016. From the onset of the epidemic 76.1 million had become infected, and 35.0 million had died. Of the 36.7 million living with HIV, 19.5 million were accessing anti-retroviral therapy. The African population represents almost $70 \%$ of total HIV cases worldwide where the majority is young Africans aged 15-24. Furthermore, Sub-Saharan Africa is the most affected region, with an estimated 25.6 million people living with HIV of which about $66 \%$ of new infection occurred in Sub-Sahara in 2015 (UNAIDS, 2016). Although, Somalia is believed to be currently a low human immunodeficiency virus (HIV) prevalent country. However, the risk factors are widespread and the number of at-risk population is also rising, which warrants special policy attention. Objective of the study: The objective of the study was to assess the knowledge, attitude, practices, and its associated factors towards HIV/AIDS among residents of Benadir Region, Somalia. Methods: A community based cross-sectional study was conducted from $1^{\text {st }}$ April to $31^{\text {st }}$ September, 2018 among 585 community members of Benadir Region. Data was collected using pretested structured face-to-face interview after taking informed written consent. Two-stage cluster sampling and systematic random sampling were used to select the districts and the households respectively. Result: Five hundred and eighty-five (585) respondents participated and gave a response rate of $96.7 \%$. Of the 585 respondents, $309(52.8 \%)$ were females while 276 (47.2\%) were males. The respondents aged between 14-78 years. It was found out that $\mathbf{7 0 \%}$ of the participants were knowledgeable, $\mathbf{5 0 . 8 \%}$ and $26.3 \%$ had favourable attitude and good practice respectively. With regard to education level, being able to read \& write, 7 times ( $A O R=7.33, C L=3.74,14.34$ ), grade 1-4, 5 times $(A O R=4.71, C L=2.82,7.88)$, grade 5-8 3 times $(A O R=3.43, C L=1.42,8.29)$ and college $\&$ above, 2 times $(A O R=1.93, C L=1.17,3.20)$ were more likely to have HIV/AIDS knowledge as compared to those who were illiterate. Being a male was 0.66 times (AOR=0.66, CL=0.48, 0.91) less likely to have a favourable attitude towards HIV/AIDS compared to females. Similarly, belonging to 35-44 age group was 4 times (AOR=3.57, $C L=1.30,9.83$ ) more likely to have favourable attitude. Having family income of 100-300 USD was 2 times (AOR=2.20, CL=1.04, 4.62), having monthly income 301-500 USD was 3 times $(A O R=3.06, C L=1.53,6.13)$ more likely to have a favourable attitude towards HIV/AIDS. Conclusion: Concerning participants' Knowledgeability, $\mathbf{7 0 \%}$ of the participants were knowledgeable, $50.8 \%$ and $26.3 \%$ had favourable attitude and good practice respectively. This shows that there is considerable limited knowledge, attitude and practices. Gender, age, marital status, level of education, occupation and monthly family income showed significant association. Recommendation: There is a need for developing policies \& strategies to raise community awareness about HIV/AIDS, to involve active community members and religious leaders to be positive role models in influencing people's behaviour.
\end{abstract}




\section{OPERATIONAL DEFINITIONS}

- Knowledge: It is the awareness of the community about HIV/AIDS. It was measured by calculating the percentage score of the 30 items and categorized as knowledgeable (if participants scored $\geq 60 \%$ ) or not knowledgeable (if participants scored $<60 \%$ ) of the total marks.

- Attitude: It is the way a community thinks and behaves toward HIV/AIDS. It was measured by calculating the percentage score of the 10 attitude items and categorized as favourable (if participants scored $\geq 60 \%$ ) or unfavorable (if participants scored $<60 \%$ ) of the total marks.

- Practice: It is the habitual community involvement to prevent HIV/AIDS. It was measured by 10 practice questions with modified two point Likert's scale. It is measured by calculating the percentage score of the 10 items and categorized as good practice (if participants scored $\geq 60 \%$ ) or poor practice (if participants scored $<60 \%$ ) of the total marks.

- Associated factors: These are issues that influence the level of community knowledge, attitude and practice.

\section{BACKGROUND}

HIV/AIDS is a global challenge that has threatened the very existence of the human race. Acquired Immune Deficiency Syndrome (AIDS) is caused by a human immunodeficiency virus (HIV) that weakens the immune system, making the body susceptible to opportunistic diseases that often lead to death. There were approximately 36.7 million people worldwide living with HIV/AIDS at the end of 2016. Of these, 2.1 million were children ( $<15$ years old).

An estimated 1.8 million individuals worldwide became newly infected with HIV in 2016 about 5,000 new infections per day. This includes 160,000 children ( $<15$ years). Most of these children live in sub-Saharan Africa and were infected by their HIV-positive mothers during pregnancy, childbirth or breastfeeding. Currently only $60 \%$ of people with HIV know their status. The remaining 40\% (over 14 million people) still need to access HIV testing services.

According to UNAIDS, globally, by 2016, 36.7 million people were living with HIV, and 1.8 million became newly infected with HIV in 2016. From the onset of the epidemic 76.1 million had become infected, and 35.0 million had died. Of the 36.7 million living with HIV, 19.5 million were accessing anti-retroviral therapy.

The first HIV case in Somali was found 1987; other four cases were reported in 1989. On the eve of the fall of former regime, the number reached 13 cases (Ahmed, et.al, 1991). Since then there was no exact community figure of HIV cases in Somalia. However, using the EPP spectrum model, UNAIDS has estimated that there are 23,936 people living with HIV in the three Somali zones, of whom 2,559 were on ART and 47 in pre ART, by the end of 2016.

As of July 2017, 20.9 million people living with HIV were accessing antiretroviral therapy (ART) globally, up from 15.8 million in June 2015, 7.5 million in 2010, and less than one million in 2000. 1 million people died from AIDS-related illnesses in 2016, bringing the total number of people who have died from AIDS-related illnesses since the start of the epidemic to 35.0 million. (UNAIDS, 2010 \& UNAIDS, 2017). The African population represents almost 70\% of total HIV cases worldwide where the majority is young Africans aged 15-24 (UNAIDS, 2010).

It is believed that the first HIV case was found in Somalia as early as 1987 during the era of former president Barre. Since then there have been some cases living with the condition. Somalia had suffered a massive population displacement and migration that is still ongoing 
during the prolonged intermittent civil war and political unrest. This period of anarchy let the nation to be at the crossroads of extreme poverty, conflict, communicable and noncommunicable diseases which were not properly monitored and managed. One of the communicable diseases which has not been studied enough is HIV/AIDS that is known to be a public health problem.

In addition, experience from other Sub-Saharan countries shows that when the rate exceeds one percent, it can quickly double or triple in a relatively short period of time. For the Somali society, this can still be avoided if prompt and effective action is taken to limit the spread of the epidemic. Good knowledge, attitude and practices (KAP) of HIV prevention are essential in order not to acquire HIV infection and to prevent the disease from spreading. A proper and well-functioning prevention of HIV requires clear and relevant information and instructions from health care givers.

\section{STATEMENT OF THE PROBLEM}

HIV/AIDS has emerged as the single most formidable challenge to public health, human rights, and development in the new millennium. There were approximately 36.7 million people worldwide living with HIV/AIDS at the end of 2016. The vast majority of people living with HIV are in low and middle-income countries. Sub-Saharan Africa is the most affected region, with an estimated 25.6 million people living with HIV of which about $66 \%$ of new infection occurred in Sub-Sahara in 2015 (UNAIDS, 2016).

Moreover, the disease is incurable and the only effective measure is prevention. Therefore, WHO strictly recommends to the nations to raise the community awareness about the mode of transmission, prevention, care and the treatment of HIV/AIDS.

Although, Somalia is believed to be currently a low human immunodeficiency virus (HIV) prevalent country. However, the risk factors are widespread and the number of at-risk population is also rising, which warrants special policy attention.

To achieve this, mass media campaigns should be widely used to expose high proportions of large populations to messages through routine use of existing media, such as television, radio, and newspapers.

Nevertheless, currently there is no systematic routine community awareness sessions in place in Somalia and no scientific study conducted so far in the country. Therefore, this lack of preventive knowledge, unfavourable attitude and poor practices increase the risk of acquiring the disease and transmitting it to others (WHO, 2011).

This study was intended to identify the level of community knowledge, attitude, practices and associated factors towards HIV/AIDS.

\section{STUDY AIM \& OBJECTIVES}

\section{Aim}

The aim of the study was to assess the knowledge, attitude, practices, and its associated factors towards HIV/AIDS among residents of Benadir Region, Somalia.

\section{Objectives}

1. To assess level of community knowledge towards HIV/AIDS among residents of Benadir region, Somalia. 
2. To assess attitude towards HIV/AIDS among residents of Benadir region, Somalia.

3. To identify factors associated with the level of knowledge, attitude \& practices towards HIV/AIDS among residents of Benadir region, Somalia.

\section{Basic knowledge about HIV/AIDS}

\section{REVIEW OF THE RELATED LITERATURE}

The human immunodeficiency virus (HIV) was unknown until the early 1980's but since then has infected millions of persons in a worldwide pandemic. The result of HIV infection is relentless destruction of the immune system leading to onset of the acquired immunodeficiency syndrome (AIDS). The AIDS pandemic has already resulted in the deaths of over half its victims. All HIV-infected persons are at risk for illness and death from opportunistic infectious and neoplastic complications because of the inevitable manifestations of AIDS (De Cock, Jaffe and Curran, 2011 and Maartens, Celum and Lewin, 2014).

Once HIV infection became established in humans, the spread of HIV has been driven by multiple factors. The advent of quick air travel in the 20th century provided a means for spread not present in past human pandemics. Urbanization has led to increased numbers of persons at risk in close proximity. Human sexual practices with promiscuity have included a larger number of persons in populations around the world. A practical and easily available means for delivery of drugs of abuse through injection became more widespread in the 20th century (De Cock, Jaffe and Curran, 2011).

The AIDS pandemic has evolved over time, with four main phases of evolution. In the initial phase, HIV emerged from endemic rural areas to spread among urban populations at an accelerating rate. In the second phase, dissemination occurred and involved definable risk groups. Behaviors in these risk groups, including sexual promiscuity and injection drug use, led to the third phase of escalation, which occurred through the 1980's. A fourth phase of stabilization has occurred in some regions such as western Europe, North America, and Australia, where control measures appear to be having a positive effect. However, some regions such as central Africa and Asia continued to experience escalation of the pandemic through the 1990's and into the 21st century (Cohen etal, 2006 \& CDC, 2006).

Globally, the incidence of new HIV infections probably peaked in 1997. At the end of the 20th century, over 21 million persons worldwide had died from AIDS, over 34 million were living with HIV infection, and over 95\% of HIV infected persons resided in developing nations. Nine countries in southern Africa, with $2 \%$ of the world's population, accounted for a third of all HIV-infected persons (De Cock, Jaffe and Curran, 2012).

At the start of the 21st century, the prevalence of HIV infection stabilized at about $0.8 \%$. The age group most affected, young persons from 15 to 24 years of age, accounted for $45 \%$ of new HIV infections. Worldwide, over half the victims of AIDS are women, and a consequence of this is perinatal infection resulting in a significant number of children born with HIV infection. The scope of the AIDS pandemic has already led to serious consequences, not only for health care systems of countries unable to cope with many AIDS victims, but also for the national economies of those countries because of the loss of young to middle aged who are economically most productive (Kilmarx, 2009).

\section{Human Immunodeficiency Virus Subtypes}

There are four major groups of HIV-1, based upon phylogenetic analysis, which likely arose from different transmission events in history among chimpanzee and gorilla primates and humans. These groups are defined as $\mathrm{M}$ (major), $\mathrm{N}$ (nonmajor and nonoutlier), $\mathrm{O}$ (outlier), and 
P. These groups are very similar to simian immunodeficiency viruses SIVcpz (M and N) and SIVgor (O and P) (Neel (2010). HIV-1 is the most widespread type worldwide.

A second retrovirus designated HIV-2 was first isolated from Portuguese patients in 1986, but it is most common in West African countries and to a lesser extent in locations in Western Europe and elsewhere that migration from West Africa occurred (Nyamweya, 2013 \& Nicolás, 2015 ). HIV-2 is believed to have been present in Africa as early as the 1940's. HIV-2, which has greater homology to simian immunodeficiency virus (SIV) than to HIV-1, appears to have become established in human populations as a zoonotic infection from the primate reservoir of sooty mangabeys (Cercocebus atys), originating from SIVsmm (Visseaux, 2016). HIV-2 infection is mainly found in West African nations, with the highest prevalence for subgroup A including Guinea-Bissau, Guinea, The Gambia, Senegal, Sierra Leone, Cape Verde, Angola, Mozambique, and Cote d'Ivoire.

\section{Mode of HIV transmission}

Considerable epidemiologic and clinical work has been performed to understand the transmission of HIV from one person to another. As in past epidemics, the spread of AIDS is facilitated by human travel. Syphilis in the 16th century, bubonic plague in the 17th century, and influenza early in the 20th century also arose from endemic foci to become widespread. Modern means of travel by jet aircraft readily available to many people provide an easy route for the spread of AIDS from one location or population to another (Smith, 1986)).

The transmission of HIV is a function of both where the virus appears in the body and how it is shed. Worldwide, heterosexual transmission accounts for the majority of cases of HIV infection. The important factors that promote heterosexual transmission include: more sexual partners; frequent change of sexual partners; unprotected sexual intercourse (lack of barrier precautions); presence of additional sexually transmitted diseases; lack of male circumcision; social vulnerability of women and young persons; economic and political instability of the community (Lamptey, 2002).

The presence of HIV in genital secretions and in blood, and to a lesser extent breast milk, is significant for spread of HIV. However, the appearance of HIV in saliva, urine, tears, and sweat is of no major clinical or social importance, as transmission of HIV through these fluids does not routinely occur, primarily because of the low concentration of HIV in these fluids (Shepard etal, 2000). Risk for HIV transmission by oral-genital sexual practices is substantially lower than that carried by genital-genital or genital-anal practices because exposure to saliva carries lower risk compared with exposure to blood because of inhibitory factors in saliva to HIV. Oral inflammation, ulceration, and bleeding may increase the risk of HIV transmission (Campo, 2006).

Though infectious particles of HIV are frequent in cerebrospinal fluid, contact with this fluid in daily life is extremely rare (Chaillon, 2014) and similarly, Cerumen (ear wax) does not carry identifiable HIV (Hanege etal, 2015).

\section{Signs and symptoms of HIV Infection}

Primary HIV infection, also known as acute retroviral syndrome, may produce a mild, selflimited, not life-threatening disease. Symptoms are subjective and reporting is variable, but likely at least a third of newly infected persons have manifestations, and some reports suggest findings in over $90 \%$. It can occur, regardless of the mode of transmission, in as few as 5 days, but typically 2 to 4 weeks following transmission in correlation with peak viremia, though onset as late as several months has been reported. Median duration of symptoms is 12 to 28 
days, subsiding over weeks. The most common symptoms, reported in over half of cases, include fever (with median maximal $38.9^{\circ} \mathrm{C}$ ), fatigue, skin rash, myalgia, and headache. The most common sign is lymphadenopathy. Other findings include pharyngitis, oral ulcers, pain on swallowing, nausea, vomiting, diarrhea, anorexia, abdominal pain, weight loss, night sweats, cough, and photophobia. The skin rash may be diffuse erythematous macular or mixed maculopapular rash, often involving the trunk. An acute meningitis may be seen in some recent infections and appear as an "aseptic meningitis." The symptoms of acute HIV infection resemble a flu-like or an infectious mononucleosis-like syndrome (Kahn and Walker, 1998; and Yerly and Hirschel, 2012).

However, an acute Epstein- Barr virus infection producing mononucleosis will have gradual onset with frequent tonsillar involvement, pharyngeal exudate, and possible liver involvement with jaundice. Laboratory studies with primary HIV infection may show lymphopenia and thrombocytopenia, but atypical lymphocytes are infrequent. Primary HIV infection can also occur with HIV-2 and in children (Kahn and Walker, 1998; and Yerly and Hirschel, 2012). Recent infection in children is usually accompanied by one or more of the following: mononucleosis-like syndrome, dermatitis, or generalized lymphadenopathy (Rouet etal, 2002).

\section{Prevention of HIV transmission}

If everyone with a risk factor for HIV infection underwent prompt HIV testing, and if everyone identified as positive for HIV received ongoing antiretroviral therapy (ART), then viremia could be suppressed to undetectable levels so that infectivity to others would be very low (Cohen etal, 2016). Decreasing infectivity to near 0 by this strategy would markedly reduce the number of new infections. Infected persons could live a near normal lifespan on antiretroviral therapy. Used together, condoms and ART could reduce HIV transmission by over 99\% ( Patel etal, 2014).

The transmission of HIV in definable risk groups allows control measures to be taken that prevent the spread of AIDS. Since HIV is primarily spread as a sexually transmissible disease, then educational efforts must be aimed at sexually active persons and must be explicit regarding the behaviors that lead to the spread of HIV. A significant number of both boys and girls become sexually active as teenagers and must be included in prevention strategies. Given that the level of promiscuity will often be difficult to modify within a population, then educational campaigns are best focused upon the use of barrier precautions, particularly condom use. All sexually active persons with more than one sexual partner, or whose partner is a member of a risk group for AIDS, should use condoms. Persons who know that they are infected with HIV should inform their sexual partners (Berg, Michelson and Safren, 2007; DiClemente etal., 2008; and Johnson etal.,2008). Sexual activity does not appear to increase with condom use (Yerly and Hirschel, 2012).

Health care providers need to offer HIV testing when the situation warrants it, in order to identify infected persons. Persons who do not know they are infected are more likely to infect others. In a study involving persons in an urban setting, over $90 \%$ of whom were seen by a physician who was a general practitioner, over half with an identifiable risk factor for HIV infection did not have HIV testing proposed to them. Over $80 \%$ of patients who had an identifiable AIDS-related illness did not have HIV testing proposed (Champenois etal, 2013). In another study from an academic hospital emergency department, only $28 \%$ of patients tested for syphilis, and only $4 \%$ tested for either gonorrhea or chlamydial infection, were also tested for HIV (Klein etal, 2014). 
Opportunities to provide HIV testing should not be missed. Socioeconomically disadvantaged persons and women in particular, are at increased risk for HIV infection. They have more limited educational opportunities. They may not have access to treatment for sexually transmitted infections and for HIV testing. They often lack access to antiretroviral therapy following infection (Jukes, Simmons and Bundy, 2008; Krishnan etal 2008, and Kidder etal, 2000).

The spread of HIV by injection drug use creates a major reservoir for HIV infection that can then be transmitted to other segments of the population, particularly heterosexual adults, including the sexual partners of injection drug users. Drug users must be educated about the risks of needle sharing. Cleaning of needles with undiluted bleach appears effective in preventing HIV transmission (Abdala etal, 2004). They can be provided with clean needles to prevent the spread of HIV, and can be advised to use condoms (Monterroso etal, 2000).

Congenital AIDS can be prevented by efforts to educate women of childbearing age about the hazards to the fetus if they are HIV-infected. Potential mothers can be provided with means of contraception. Antiretroviral therapy for mothers can reduce perinatal HIV transmission. Confidential HIV testing should be made available along with counseling services to persons in all risk groups to encourage voluntary testing and prevent unknowing transmission of HIV (Khalsa, 2006).

Transmission of HIV through blood product therapy has become vanishingly rare when screening and testing of donors is applied. Such screening is costly. Since HIV infection is not spread by casual contact in public places, households, or in the workplace, no modifications of routine activities of daily living or work practices is necessary. Insect vectors do not spread HIV, and insect control programs will have no effect upon HIV transmission in a population.

HIV/AIDS prevention programs have successfully produced long-term behavior change with reduction in incidence of HIV infection (Holtgrave, 2007). In order for such programs to be effective, several principles must be applied: sustained interventions are more likely to lead to sustained behavior change; more intense interventions are more likely to result in greater risk reduction; accessibility to devices (such as clean needles and condoms) that are necessary to safer practices reduces the risk for HIV infection; modification of community norms appears to enhance behavior change; and explicit HIV prevention programs must be provided prior to the time that adolescents become sexually active (CDC, 2006).

\section{Aids Risk Reduction Model (ARRM)}

The AIDS Risk Reduction Model (ARRM) provides a framework for explaining and predicting the behavior change effects of an individual specifically in relationship to the sexual transmission of HIV/AIDS. A three stage model, the ARRM incorporates several variables from other behavior change theories including the Health Belief Model theory, emotional influences and interpersonal processes (Catania et al,1990). The stages as well as factors that influence the successful completion of each stage are as follows:

Stage 1: Recognition and labeling of one's behavior as high risk. This is based on knowledge of sexual activities associated with HIV transmission, belief that one is personally susceptible to contracting HIV and belief that HIV/AIDS is undesirable.

Stage 2: Making a commitment to reduce high-risk sexual contacts and to increase low risk activities. The main assumptions in this stage include cost and benefit analysis of the risk, importance of sexual practice as seen by the individual and its potential risk, and knowledge of 
the healthy utility as well as social factors (group norms and social support), are believed to influence an individual's cost and benefit and self -efficacy beliefs.

Stage 3: Taking action. This stage is broken down into three phases: Information seeking; obtaining remedies and enacting solutions. Depending on the individual, phases may occur concurrently or phases may be skipped. The main areas that are of importance in this stage are the place of social networks and problem solving choices; prior experiences with problems and solutions; level of self-esteem; resource requirements of acquiring help; ability to communicate verbally with sexual partner; and sexual partner's beliefs and behaviors.

\section{Methods to Reduce Rates of HIV Transmission}

Treat HIV infection as an illness, not as a social stigma; reduce levels of poverty in society that lead to increased risks through drug abuse and promiscuity; provide HIV testing and counseling to identify infected persons who can reduce their risk to others; provide educational programs for children and adults which describe how to avoid sexually transmitted diseases; Promote sexual barrier precautions among high risk commercial sex workers and clients; Provide clean needles for injection drug users; Offer male circumcision; Create health care programs with ongoing support to provide antiretroviral therapy to extend life and reduce HIV transmission rates; Give HIV-infected pregnant women antiretroviral therapy to reduce perinatal HIV Transmission; Consider pre-exposure prophylaxis with antiretroviral drugs; Provide antiretroviral therapy suppressing viral load to undetectable levels.

\section{Knowledge of condom sources among youth}

While condoms are the best weapons against HIV transmission, studies continue to show limited use of this barrier method in sexual intercourse in sub-Saharan Africa (Eaton, et. al. 2002). Several factors, such as low availability, cost, lack of education about condoms and how to use them, and relationship factors contribute to low usage. In particular, Kenyans have often received conflicting messages about condom use. Many religious leaders have expressed opposition to condom use.

\section{Treatment for HIV/AIDS}

A variety of therapies has been developed since 1984 for persons infected with HIV.

\section{Antiretroviral therapy}

Antiretroviral therapy (ART) is the use of HIV medicines to treat HIV infection. People on ART take a combination of HIV medicines (called an HIV regimen) every day. ART is recommended for everyone who has HIV. ART can't cure HIV, but HIV medicines help people with HIV live longer, healthier lives. ART also reduces the risk of HIV transmission.

\section{How HIV medicines work}

HIV attacks and destroys the infection-fighting CD4 cells of the immune system. Loss of CD4 cells makes it hard for the body to fight off infections and certain HIV-related cancers.

HIV medicines prevent HIV from multiplying (making copies of itself), which reduces the amount of HIV in the body. Having less HIV in the body gives the immune system a chance to recover. Even though there is still some HIV in the body, the immune system is strong enough to fight off infections and certain HIV-related cancers. By reducing the amount of HIV in the body, HIV medicines also reduce the risk of HIV transmission. 


\section{Time to start taking HIV medicines}

People with HIV should start ART as soon as possible. In people with the following conditions, it's especially important to start ART right away: pregnancy, AIDS, certain HIV-related illnesses and coinfections, and recent HIV infection.

\section{Medicines are included in HIV regimen}

There are many HIV medicines available for HIV regimens. The HIV medicines are grouped into seven drug classes according to how they fight HIV. A person's initial HIV regimen usually includes three HIV medicines from at least two different HIV drug classes. Selection of an HIV regimen depends on several factors, including possible side effects of HIV medicines and potential drug interactions between medicines. Because the needs of people with HIV vary, there are several HIV regimens to choose from.

\section{Attitude towards HIV/AIDS Prevention and Care}

Good knowledge, attitudes and practices (KAP) of HIV prevention are essential in order not to acquire HIV infection and to prevent the disease from spreading. A proper and well-functioning prevention of HIV requires clear and relevant information and instructions from health care givers.

\section{Myths and misconceptions}

In addition to knowing about effective ways to avoid contracting HIV/AIDS, it is also useful to be able to identify incorrect beliefs about AIDS to eliminate misconceptions. Common misconceptions about AIDS include the idea that all HIV infected people appear ill and the belief that the virus can be transmitted through mosquito or other insect's bites, by sharing food with someone who is infected or by witch craft or other supernatural means.

HIV myths and misconceptions are the product of misinformation and ignorance. Common misconceptions among the Somalis, especially the non-schooled include Pseudoimmunity which is deeply rooted belief in which some of the people believe that Muslims who practice Islam would never get infected with HIV/AIDS (Dahie and Heyle, 2018).

\section{Discriminatory attitudes toward PLWHA}

The stigma associated with HIV has long undermined HIV prevention and treatment efforts (UNAIDS, 2008). HIV-related stigma inhibits open discussion of the epidemic, and fear of discrimination or disapproval may also deter individuals from seeking the services they need. In some instances, individuals may actually avoid taking steps to protect against HIV transmission out of fear that they may be considered potentially infectious or thought to belong to a marginalized group that has been heavily affected by the epidemic (The Kenya AIDS epidemic update, 2011).

Negative and discriminatory attitudes towards people living with HIV/AIDS (PLWHA) are one of the biggest challenges experienced by people suffering from HIV, and these attitudes have been regarded as a serious threat to the fundamental rights of all infected people who are affected or associated with this disease in Somalia.

\section{Practice regarding HIV/AIDS}

Good practice is paramount in the prevention, treatment and care of HIV/AIDS. Good practices include periodic HIV screening, participation of VCT sessions, compliance of preventive and treatment measures. 
Confidential HIV testing should be made available along with counseling services to persons in all risk groups to encourage voluntary testing and prevent unknowing transmission of HIV (Khalsa, 2006). Confidential HIV testing should be made available along with counseling services to persons in all risk groups to encourage voluntary testing and prevent unknowing transmission of HIV (Khalsa, 2006). If everyone with a risk factor for HIV infection underwent prompt HIV testing, and if everyone identified as positive for HIV received ongoing antiretroviral therapy (ART), then viremia could be suppressed to undetectable levels so that infectivity to others would be very low (Cohen etal., 2016). Decreasing infectivity to near 0 by this strategy would markedly reduce the number of new infections. Infected persons could live a near normal lifespan on antiretroviral therapy.

VCT stands for voluntary counseling and testing. It is an HIV intervention that includes both voluntary pre- and post-test counselling and voluntary HIV testing. People, of their own free will, opt for VCT, and it provides them with an opportunity to confidentially explore and understand their HIV risks and to learn their HIV test results. VCT is a cost effective intervention in high-prevalence settings and that it motivates a positive behaviour change among both HIV-positive and HIV-negative persons. The burden of handling HIV infections has increased to levels beyond the current capacity of health systems to cope with it. Thus advocacy efforts have intensified to mobilize resources and to extend use of interventions that evidence has shown to be effective, with the result that NGOs and partners have expanded VCT services.

Medication adherence is another important practice. It means sticking firmly to an HIV regimen taking HIV medicines every day and exactly as prescribed. HIV medicines prevent HIV from multiplying, which protects the immune system and reduces the risk of both drug resistance and HIV treatment failure. Medication adherence lets HIV medicines do their job.

\section{Study Area}

\section{METHODOLOGY}

The study was conducted in Benadir region which is an administrative region (gobol) in southeastern Somalia. It covers the same area as the city of Mogadishu, Somalia's capital. It is Located in the coastal Benadir region on the Indian Ocean in southeastern Somalia. It is the largest and most populated city in the country that has over 2.5 million residents and accounts for about one-quarter of the country's total population count. It consists of 17 districts: Wadajir, Dharkenley, Daynile, Wardigley, Howl Wadaag, Waberi, Hamar Jajab, Hamar Weyne, Bondere, Karaan, Yaqshid, Heliwa, Hodan, Shibis, Abdiaziz, Shangani \& Kahda.

\section{Study Design}

A community based cross-sectional study was conducted from $1^{\text {st }}$ April to $31^{\text {st }}$ September, 2018. Data on socio-demographic characteristics, knowledge, attitude, practice and their associated factors towards HIV/AIDS were collected using structured questionnaires.

\section{Sample Size Determination}

Sample size was determined using a single population proportion formula assuming unknown prevalence rate (i.e. $50 \%$ ) since there is no earlier reports with $\pm 5 \%$ precision, $95 \%$ confidence level, 1.5 design effect and 5\% non-response rate which resulted in 605 study participants.

$\mathrm{p}=$ proportional $=0.5$ or $50 \%$

$\mathrm{z}=$ standard normal distribution for $95 \%$ level (1.96)

$\mathrm{d}=$ Margin of error (accepted error) $=0.05$, 


\section{design effect $=1.5$}

Therefore, $\mathrm{n}=\mathrm{Z}_{\alpha / 2} \mathrm{P}(1-\mathrm{P}) / \mathrm{d}^{2}$

$\mathrm{n}=(1.96)^{2 *}(0.5) *(1-0.5) *(1.5) /(0.05)^{2}=576$.

Considering 5\% non-respondent rate $=576+5 \%=605$.

A total of 605 were selected.

\section{Sampling Technique}

Two-stage cluster sampling method was used in which the 17 districts of Benadir region were taken as clusters. Then 4 of the districts were randomly selected from these 17 districts whose households were then systematically selected on a proportionate basis. After getting the number of households from the concerned district administrative offices, the calculated sample size was allocated proportionately to the size of population in each administrative zone.

Then, villages from each administrative district were selected using simple random sampling and households from each selected village were chosen using systematic random sampling.

The first household was chosen by lottery method, and systematic sampling technique was used in the subsequent households.

Similarly, the first person to be encountered in the household who met the criteria was interviewed. For those who failed, a second person was interviewed and if there were more than one individual meeting the criteria in the same household, lottery method was used. In their absence, a respondent was searched from the next household.

\begin{tabular}{|l|c|c|c|}
\hline District & Total Population & Total Households & Sampled Households \\
\hline Hodan & 71,590 & 11,932 & 152 \\
\hline Dharkenley & 40,983 & 6,831 & 87 \\
\hline Yaqshid & 128,488 & 21,415 & 273 \\
\hline Heliwa & 43,420 & 7,237 & 93 \\
\hline Total & 284,481 & 47,415 & 605 \\
\hline
\end{tabular}

\section{Eligibility Criteria}

Respondents were eligible if their age was over 15 years, and not too ill to be interviewed, willing to participate and were available during the data collection period; and have lived at least six months in Benadir Region. On the other hand, participants were excluded if they were homeless and have clinically proven HIV/AIDS positive.

\section{Study Instrument}

The study instruments were structured categorical questionnaires. Questionnaires were administered to the study participants who consented and fulfilled the eligibility criteria. Questionnaires consist of four sections namely: socio-demographic, knowledge, attitude and practice sections.

A structured categorical questionnaire was developed, which was used to conduct the pilot study; later, it was validated and used in the main study. The questionnaire was made up of four parts. In part I, questions were directed toward socio-demographic characteristics of the respondent, while questions in parts II, III, \& IV focused to respondent's knowledge, attitude and practice respectively. 


\section{Demographic characteristics of the respondent}

In this part seven questions on demographic characteristics were discussed to identify characteristics of the respondent.

\section{Knowledge regarding HIV/AIDS}

There were thirty questions in this part of which each question had two choices (correct \& incorrect). The correct answer was given one score, whereas a zero score was given for a wrong answer. The researchers adopted new cut-off points of which $\leq 59 \%(0-17)$ was taken as non-knowledgeable while $\geq 60 \%$ (18-30) was regarded as knowledgeable.

\section{Attitude towards HIV/AIDS}

There were ten questions in this part of which each question had two choices. A correct answer which was given one score, whereas a zero score was given for a wrong answer. Cut-off points between $0-59 \%(0-5)$ were regarded as unfavourable attitude while those between $60-100 \%$ (6-10) were regarded as favourable attitude.

\section{Practice regarding HIV/AIDS}

In this part, similarly ten questions were included of which each question had two choices. A correct answer was given one score, whereas a zero score was given for a wrong answer. Cutoff points between 0-59\% (0-5) were regarded as unfavourable attitude while those between $60-100 \%$ (6-10) were regarded as favourable attitude.

\section{Data Collection}

Data were collected using pretested structured questionnaires after taking informed written consent from the respondent. Eight data collectors and two supervisors collected the data by moving systematically from house to house after they have taken two days training.

\section{Quality Assurance Procedures}

Senior nursing students who fluently speak both English and Somali languages were selected as research assistants and then trained for two days about the study objectives, interviewing techniques, clinical features of HIV/AIDS, data collection tools, ethical issues, responsibilities of data collectors and quality control.

Soft copies of data were coded and hard copies locked in a locker in the office of the principal researchers. Research team had access to data only when permission was granted by the principal researchers.

The returned and completed tools have been cross-checked by the principal researchers to ascertain their completeness. Questionnaires with missing data were re-administered to the respondents for correction.

\section{Data Management and Analysis}

The data were entered into and analyzed with SPSS version 16. Besides descriptive statistics, odds ratio with 95\% confidence interval were calculated and $\mathrm{P}<0.05$ was considered statistically significant. Finally, multivariable logistic regression analysis was performed to indicate the independent predictors of knowledge, attitude and practice.

\section{Ethical considerations}

Ethical clearance for this research was obtained from the Ministry of Health, Department of Public health research. 


\section{Informed consent}

The respondents were requested to participate in the research by answering the questionnaire through the research assistants. Their participation was voluntary and they had the freedom to withdraw at any time if they might feel so and there was no victimization for any refusal to participate or withdrawal.

\section{Privacy and Confidentiality}

Respondents were granted full privacy and confidentiality. All information they provided to the interviewers was strictly kept confidential and records securely stored in a locker.

\section{Anonymity}

The participant's name and identity were kept anonymous. Only their responses and findings were presented in the study.

\section{RESULT}

Five hundred and eighty-five (585) respondents participated and gave a response rate of $96.7 \%$.

\section{Socio demographic characteristics of respondents}

Of the 585 respondents, 309 (52.8\%) were females while $276(47.2 \%)$ were males. The respondents aged between $14-78$ years with 26.5 as a mean $(S D=8.33)$.

Almost half of the respondents (49.6\%) were single whose majority had education levels between secondary and university (62.9\%).

More than one thirds (36.2\%) of the respondents were students. Aside this, more than half $(51.1 \%)$ of them had an average family income that ranged between 100-300 USD (Table 1). 
Table 1. Socio demographic characteristics of respondents

\begin{tabular}{|c|c|c|c|}
\hline \multicolumn{2}{|c|}{ Respondent's characteristics } & No & $\%$ \\
\hline \multirow{4}{*}{ Address category } & Dharkenley & 87 & 14.9 \\
\hline & Heliwa & 92 & 15.7 \\
\hline & Hodan & 152 & 26.0 \\
\hline & Yaqshid & 254 & 63.4 \\
\hline \multirow{2}{*}{ Gender } & Male & 276 & 47.2 \\
\hline & Female & 309 & 52.8 \\
\hline \multirow[t]{5}{*}{ Age category } & $<18$ & 26 & 4.4 \\
\hline & $18-24$ & 254 & 43.4 \\
\hline & $25-34$ & 226 & 38.6 \\
\hline & $35-44$ & 56 & 9.6 \\
\hline & $>44$ & 23 & 3.9 \\
\hline \multirow[t]{4}{*}{ Marital status } & Single & 290 & 49.6 \\
\hline & Married & 263 & 44.9 \\
\hline & Divorced & 25 & 4.3 \\
\hline & Widow & 7 & 1.2 \\
\hline \multirow[t]{6}{*}{ Level of education } & Unable to read \& write & 48 & 8.2 \\
\hline & Able to read \& write & 105 & 17.9 \\
\hline & Grade 1-4 & 24 & 4.1 \\
\hline & Grade 5-8 & 40 & 6.8 \\
\hline & Grade 9-12 & 136 & 23.2 \\
\hline & College \& above & 232 & 39.7 \\
\hline \multirow[t]{7}{*}{ Occupation } & Housewife & 152 & 26.0 \\
\hline & Student & 212 & 36.2 \\
\hline & Merchant & 60 & 10.3 \\
\hline & Farmer & 7 & 1.2 \\
\hline & Government employee & 76 & 13.0 \\
\hline & Private employee & 47 & 8.0 \\
\hline & Laborer & 31 & 5.3 \\
\hline \multirow{4}{*}{$\begin{array}{l}\text { Monthly family income (in } \\
\text { USD) }\end{array}$} & $<100$ & 123 & 21.0 \\
\hline & $100-300$ & 299 & 51.1 \\
\hline & $301-500$ & 121 & 20.7 \\
\hline & $>500$ & 42 & 7.2 \\
\hline
\end{tabular}

\section{Participants' knowledge on HIV/AIDS}

From the table below (Table 2), majority 396 (67.7\%) of the participants correctly that HIV is a disease that harms humans' immune system by destroying the white cells which fight infection. Similarly, about two-thirds 387 (66.2\%) of participants stated that having unprotected sex, many sexual partners, sharing sharp objects and having another sexually transmitted disease are risk factors for HIV transmission. Furthermore, a more than half 327 (55.9\%) of the respondents correctly answered questions related to the signs \& symptoms of HIV/AIDS. On the other hand, majority 460 (78.6\%) of the respondents have mentioned avoid sharing syringes, condom use \& use of disposable gloves as modes of HIV prevention. With regard to HIV/AIDS treatment, more than two-thirds $402(68.7 \%)$ of the respondents have chosen that there is a treatment for HIV/AIDS that is taken throughout life to help people living with the infection stay healthy.

Table 2. Frequency distribution of participants' response of HIV/AIDS knowledge

\begin{tabular}{l|c|c}
\hline \multirow{2}{*}{ Variable } & Levels of Knowledge & \\
\cline { 2 - 3 } & Knowledgeable & Non-knowledgeable \\
\hline What is HIV/AIDS & $396(67.7 \%)$ & $189(32.3 \%)$ \\
\hline What are the causes/risk factors of HIV/AIDS & $387(66.2 \%)$ & $198(33.2 \%)$ \\
\hline What are the modes of HIV transmission & $482(82.4 \%)$ & $103(17.6 \%)$ \\
\hline What are signs \& symptoms of HIV/AIDS & $327(55.9 \%)$ & $258(44.1 \%)$ \\
\hline What are methods of prevention & $460(78.6 \%)$ & $125(21.4 \%)$ \\
\hline What is the HIV/AIDS treatment & $402(68.7 \%)$ & $183(31.3 \%)$ \\
\hline Overall & $\mathbf{4 0 9} \mathbf{( 7 0 . 0 \% )}$ & $\mathbf{1 7 6}(\mathbf{3 0 . 0 \% )}$ \\
\hline
\end{tabular}




\section{Attitude of participants towards HIV/AIDS}

Majority of the respondents 309 (52.8\%) have favourable attitude towards HIV screening, however, only small portion $166(28.4 \%)$ of the participants favored to maintain sexual relationship with their partners living with HIV/AIDS, although more than half of the respondents had the willingness to care their relatives living with the infection.

Table 3. Frequency distribution of participants' attitude response towards HIV/AIDS

\begin{tabular}{l|c|c}
\hline \multirow{2}{*}{ Variable } & \multicolumn{2}{|c}{ Levels of attitude } \\
\cline { 2 - 3 } & Favourable & Non-favourable \\
\hline Attitude towards HIV Screening & $309(52.8 \%)$ & $276(47.2 \%)$ \\
\hline Attitude towards maintaining relationships with PLWHs & $166(28.4 \%)$ & $419(71.6 \%)$ \\
\hline Attitude towards willingness to Care PLWH & $339(57.9 \%)$ & $246(42.1 \%)$ \\
\hline Overall attitude level & $\mathbf{2 9 7 ( 5 0 . 8 \% )}$ & $\mathbf{2 8 8 ( 4 9 . 2 \% )}$ \\
\hline
\end{tabular}

\section{Practice level of participants towards HIV/AIDS preventive measures}

An interest point is that only 134 (22.9\%) of the respondents ever visited VCT centers while a very small number of participants $127(21.7 \%)$ had shown their compliance of preventive measures.

\begin{tabular}{l|c|c}
\multirow{2}{*}{ Table 4. Frequency distribution of participants' practice response towards HIV/AIDS } \\
\cline { 2 - 3 } & \multicolumn{2}{|c}{ Levels of practice } \\
\cline { 2 - 3 } & Good & Poor \\
\hline VCT Visit & $134(22.9 \%)$ & $451(77.1 \%)$ \\
\hline Compliance of preventive measures & $127(21.7 \%)$ & $458(78.3 \%)$ \\
\hline Overall practice level & $\mathbf{1 5 4 ( 2 6 . 3 \% )}$ & $\mathbf{4 3 1 ( 7 3 . 7 \% )}$ \\
\hline
\end{tabular}

\section{Factors associated with participant's knowledge level towards HIV/AIDS}

Among variables entered in the bi-variate analysis, marital status, level of education, occupation, and average monthly income of the respondents showed significant association at P-value of $<0.05$.

Variables with P-value $\leq 0.05$ were entered in the multivariate logistic regression analysis and some of the above association at bivariate level did not exist after adjustment for other variables.

In the multivariate logistic regression analysis, participants who were able to read \& write, 7 times $(\mathrm{AOR}=7.33, \mathrm{CL}=3.74,14.34)$, grade $1-4,5$ times $(\mathrm{AOR}=4.71, \mathrm{CL}=2.82,7.88)$, grade 5-8 3 times (AOR=3.43, $\mathrm{CL}=1.42,8.29$ ) and college $\&$ above, 2 times ( $\mathrm{AOR}=1.93, \mathrm{CL}=1.17,3.20$ ) were more likely to have HIV/AIDS knowledge as compared to those who were illiterate. Earning average monthly family income of 100-300 USD was 4 times (AOR=3.54, $C L=1.46,8.60$ ) more likely to be knowledgeable compared to those who earn less than 100USD (Table 5). 
Table 5. Bivariate and multivariate logistic regression analysis for predicting factors associated with HIV/AIDS knowledge among community members of Benadir region, $2018(\mathrm{~N}=585)$

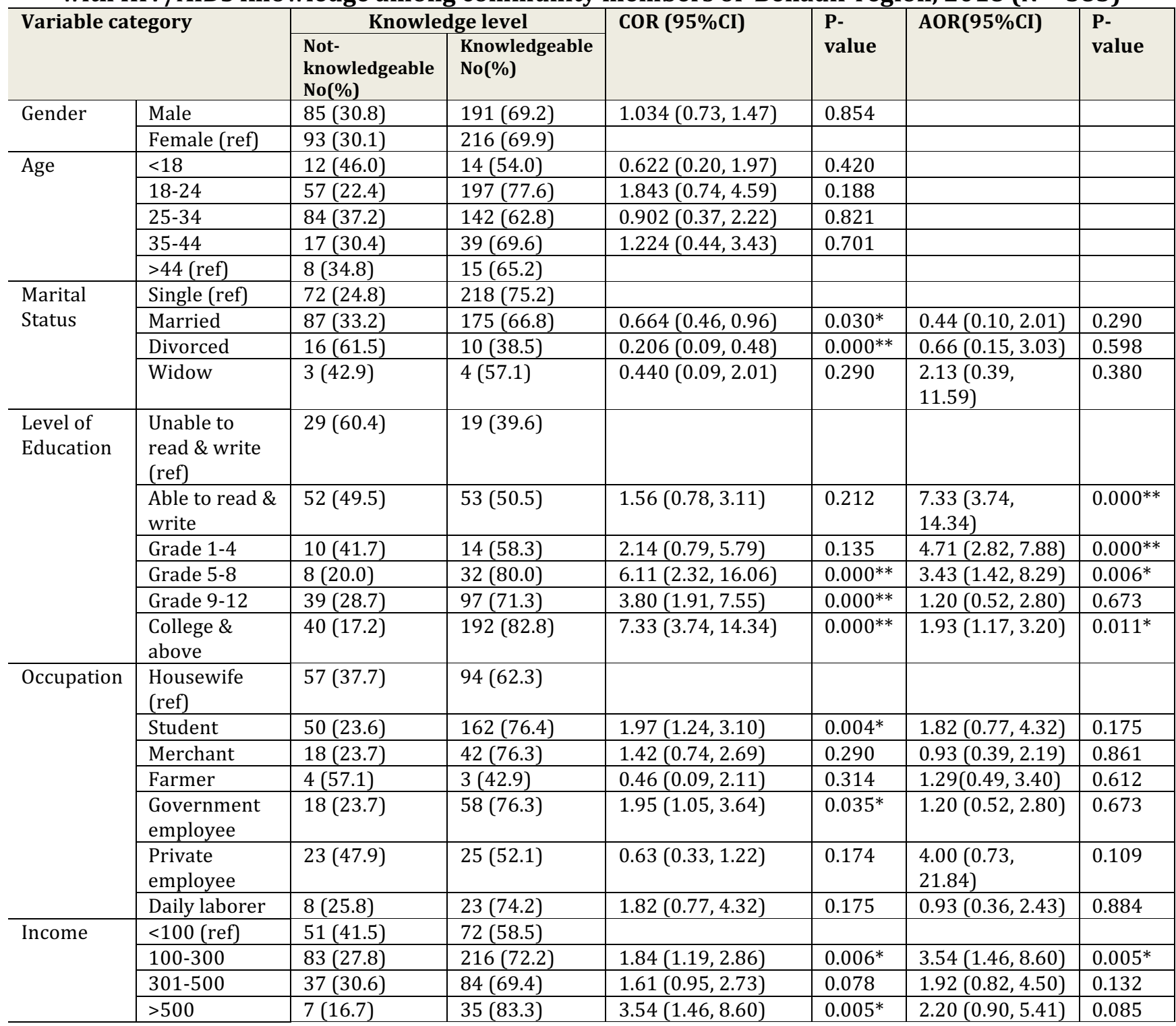

* For Significant variables

** For highly significant variables

Statistically significant at $\mathrm{p}<0.05$.

\section{Factors associated with participant's attitude level towards HIV/AIDS}

Gender, age and monthly family income showed significant association when entered in the bivariate analysis. Likewise, the same variables showed significant association when entered in multivariate logistic regression analysis. Being a male is 0.66 times $(\mathrm{AOR}=0.66, \mathrm{CL}=0.48,0.91$ ) less likely to have a favourable attitude towards HIV/AIDS compared to females. Similarly, belonging to 35-44 age group is 3.5 times ( $\mathrm{AOR}=3.57, \mathrm{CL}=1.30,9.83$ ) more likely to have favourable attitude.

Having family income of 100-300 USD was 2 times (AOR=2.20, CL=1.04, 4.62), having monthly income 301-500USD was 3 times $(A O R=3.06, C L=1.53,6.13)$ more likely to have a favourable attitude towards HIV/AIDS. However, having monthly an income of >500USD didn't show significant association in multivariate analysis (Table 6). 
Dahie, H. A., \& Heyle, A. A. (2019). Knowledge, attitude, practices and their associated factors towards HIV/AIDS among residents of Benadir Region, Somalia. Advances in Social Sciences Research Journal, 6(1) 240-261.

Table 6. Bivariate and multivariate logistic regression analysis for predicting factors associated with level of attitude towards HIV/AIDS among community members of Benadir region, 2018 (N = 585)

\begin{tabular}{|c|c|c|c|c|c|c|c|}
\hline \multicolumn{2}{|c|}{ Variable category } & \multirow{2}{*}{\begin{tabular}{l|}
$\begin{array}{l}\text { Attitude level } \\
\text { Unfavourable } \\
\text { No(\%) }\end{array}$ \\
$151(54.7)$ \\
\end{tabular}} & \multirow{2}{*}{$\begin{array}{l}\text { Favourable } \\
\text { No(\%) }\end{array}$} & \multirow{2}{*}{$\begin{array}{l}\text { COR (95\%CI) } \\
0.659(0.48, \\
0.91) \\
\end{array}$} & \multirow{2}{*}{$\begin{array}{l}\begin{array}{l}\text { P- } \\
\text { value }\end{array} \\
0.012^{*}\end{array}$} & \multirow{2}{*}{$\begin{array}{l}\text { AOR(95\%CI) } \\
0.66(0.48,0.91)\end{array}$} & \multirow{2}{*}{$\begin{array}{l}\begin{array}{l}P- \\
\text { value }\end{array} \\
0.047^{*}\end{array}$} \\
\hline Gender & Male & & & & & & \\
\hline & Female (ref) & $137(44.3)$ & $172(55.7)$ & & & & \\
\hline \multirow[t]{5}{*}{ Age } & $<18$ & $18(69.2)$ & $8(30.8)$ & $0.69(0.21,2.25)$ & 0.540 & $0.69(0.21,2.25)$ & 0.540 \\
\hline & $18-24$ & $130(51.2)$ & $124(48.8)$ & $1.48(0.62,3.55)$ & 0.376 & $1.48(0.62,3.55)$ & 0.376 \\
\hline & $25-34$ & $109(48.2)$ & $117(51.8)$ & $1.67(0.69,4.01)$ & 0.252 & $1.67(0.70,4.01)$ & 0.252 \\
\hline & $35-44$ & $17(30.4)$ & $39(69.6)$ & $3.56(1.30,9.82)$ & $0.014 *$ & $3.57(1.30,9.83)$ & $0.014 *$ \\
\hline & $>44$ (ref) & $14(60.9)$ & $9(39.1)$ & & & & \\
\hline \multirow{4}{*}{$\begin{array}{l}\text { Marital } \\
\text { Status }\end{array}$} & Single (ref) & $149(51.4)$ & $141(48.6)$ & & & & \\
\hline & Married & $127(48.5)$ & $135(51.5)$ & $1.12(0.80,1.59)$ & 0.495 & & \\
\hline & Divorced & $9(34.6)$ & $17(65.4)$ & $1.99(0.86,4.62)$ & 0.107 & & \\
\hline & Widow & $3(42.9)$ & $4(57.1)$ & $1.40(0.31,6.41)$ & 0.657 & & \\
\hline \multirow{6}{*}{$\begin{array}{l}\text { Level of } \\
\text { Education }\end{array}$} & $\begin{array}{l}\text { Unable to read \& write } \\
\text { (ref) }\end{array}$ & $30(62.5)$ & $18(37.5)$ & & & & \\
\hline & Able to read \& write & $51(48.6)$ & $54(51.4)$ & $1.77(0.88,3.55)$ & 0.111 & & \\
\hline & Grade 1-4 & $13(54.2)$ & $11(45.8)$ & $1.41(0.52,3.81)$ & 0.497 & & \\
\hline & Grade 5-8 & $19(47.5)$ & $21(52.5)$ & $\begin{array}{l}1.84(0.79 \\
4.32)\end{array}$ & 0.160 & & \\
\hline & Grade $9-12$ & $65(47.8)$ & $71(52.2)$ & $1.82(0.93,3.57)$ & 0.082 & & \\
\hline & College \& above & $110(47.4)$ & $122(52.6)$ & $1.85(0.98,3.50)$ & 0.059 & & \\
\hline \multirow[t]{7}{*}{ Occupation } & Housewife (ref) & $75(49.7)$ & $76(50.3)$ & & & & \\
\hline & Student & $105(49.5)$ & $107(50.5)$ & $1.01(0.66,1.58)$ & 0.979 & & \\
\hline & Merchant & $32(53.3)$ & $28(46.7)$ & $0.86(0.47,1.57)$ & 0.631 & & \\
\hline & Farmer & $2(28.6)$ & $5(71.4)$ & $\begin{array}{l}2.47(0.46 \\
13.11)\end{array}$ & 0.289 & & \\
\hline & Government employee & $39(51.3)$ & $37(48.7)$ & $0.94(0.54,1.63)$ & 0.815 & & \\
\hline & Private employee & $23(48.9)$ & $24(51.1)$ & $1.03(0.54,1.98)$ & 0.930 & & \\
\hline & Daily laborer & $12(37.5)$ & $20(62.5)$ & $1.65(0.75,3.60)$ & 0.213 & & \\
\hline \multirow[t]{4}{*}{ Income } & $<100$ (ref) & $61(49.6)$ & $62(50.4)$ & & & & \\
\hline & $100-300$ & $173(57.9)$ & $126(42.1)$ & $0.72(0.47,1.09)$ & 0.121 & $2.20(1.04,4.62)$ & 0.038* \\
\hline & $301-500$ & $41(33.9)$ & $80(66.1)$ & $1.92(1.15,3.22)$ & $0.013^{*}$ & $3.06(1.53,6.13)$ & $0.002^{*}$ \\
\hline & $>500$ & $13(31.0)$ & $29(69.0)$ & $2.20(1.04,4.62)$ & $0.038^{*}$ & $1.14(0.54,2.43$ & 0.728 \\
\hline
\end{tabular}

* For Significant variables

** For highly significant variables

Statistically significant at $\mathrm{p}<0.05$.

\section{Factors associated with participants' practice level towards HIV/AIDS}

There was no any significant association between respondent's characteristics and practice level (Table 7). However, $81.3 \%$ of those with poor practice were unable to read and write while only $18.7 \%$ of the respondents were able to read and write and had good practice. 
Table 7. Bivariate and multivariate logistic regression analysis for predicting factors associated with practice level towards HIV/AIDS among community members of Benadir region, 2018 (N = 585)

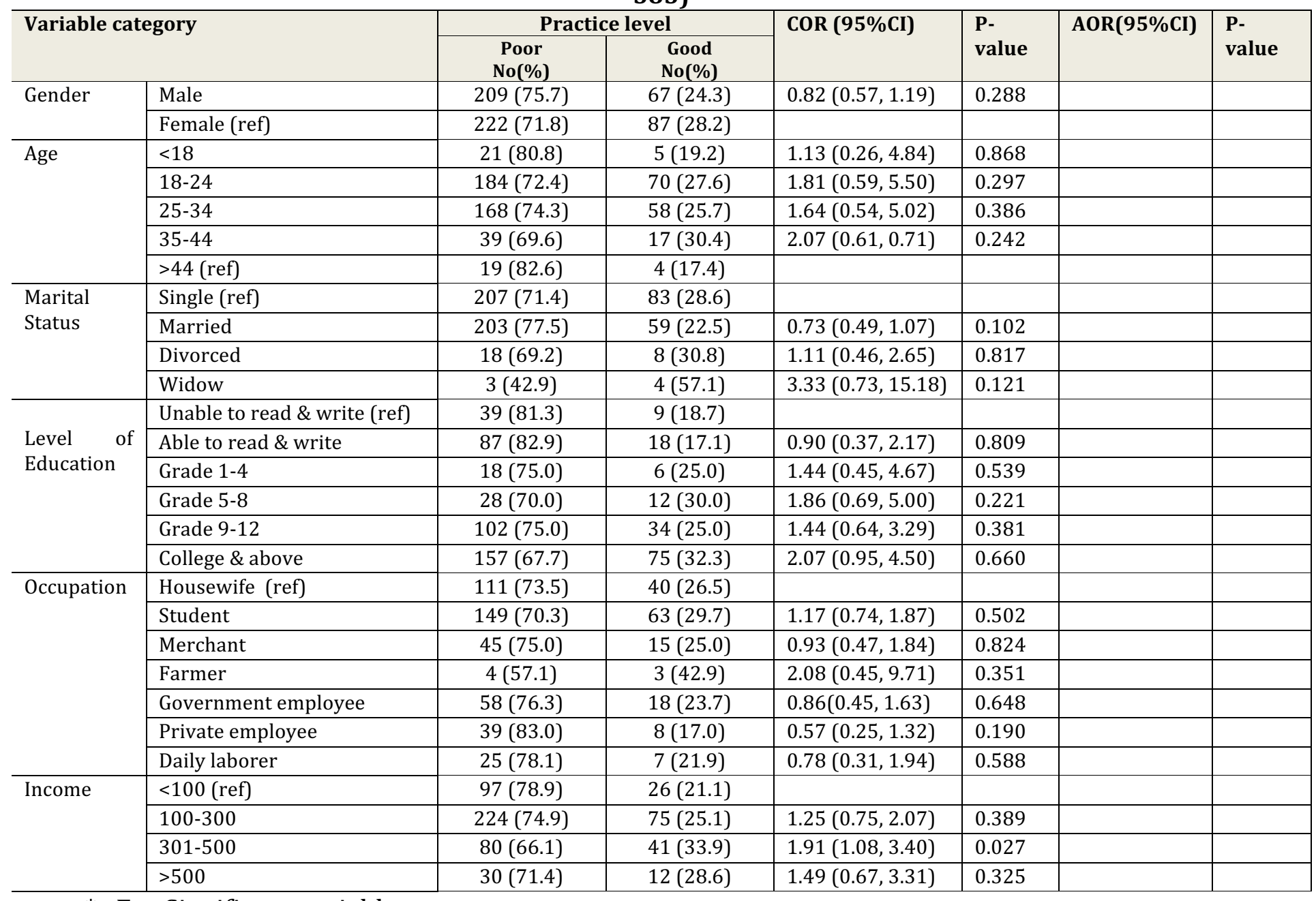

* For Significant variables

** For highly significant variables

Statistically significant at $\mathrm{p}<0.05$.

\section{Knowledge}

\section{DISCUSSION}

Valid knowledge, attitude and practices about HIV/AIDS are important in the prevention and treatment of the disease. This is the first community based study done on general population in the capital city to assess knowledge, attitude, practice and associated factors of the population on HIV/AIDS. This study has found out that overall level of respondent knowledgeability was 70\%. A comparable study was not found in the country. However, several studies conducted in the neighboring countries revealed a higher figure than this. One study conducted in Nairobi, Kenya in 2014 reported that $78.4 \%$ and $80.4 \%$ for secondary and tertiary students respectively. Similarly, another study conducted in Ethiopia in 2003 reported as higher as 95.5\% knowledgeability among tertiary students in Gambella. Although there is difference, it might be due to the difference in sociodemographic characteristics of the respondents.

On the other hand, there were also widespread misconceptions among the interviewed respondents where $42.3 \%$ of study participants stated that mosquito bite, hugging, sharing of meals, clothes and latrine with people living with HIV/AIDs could transmit the disease. 
Among variables analyzed, marital status, level of education, occupation, and average monthly income of the respondents showed significant association at $\mathrm{P}$-value of $<0.05$.

\section{Attitude}

With regard to attitude, the study confirmed that only $50.8 \%$ of the respondents had favourable attitude towards helpful facts and preventive strategies of HIV/AIDS. This means that almost half of the participants had unfavorable attitude. This also shows that discriminatory attitudes were present in a considerable proportion (49.2\%) of the participants. Good attitudes of the people towards HIV/AIDS are very important for HIV/AIDS prevention, care and support. However, this study is in line with several other studies which were conducted in the region that have also shown that a quit large number of people have negative attitudes towards HIV/AIDS and the people with the disease (Khan, Ishaq, Khan, and Ishaq, 2008).

Nearly half of the respondents (43.7\%) wouldn't mind having their HIV status been tested. Almost one-third of the respondents agreed that PLWHA should be expelled from the community while less than one-third of the study participants were willing to maintain their relation if their friend gets infected.

Result of the study exhibited that majority of the participants had some form of negative and discriminatory attitudes towards HIV/AIDS and people living with the disease. The problem of negative attitudes towards PLWA has been well researched in sub-Saharan Africa and studies carried out in the region have shown consistently that it affects both adults and youth (Aggleton, 2000).

A study conducted in 2014 by Global information and education on HIV and AIDS found out that in $35 \%$ of countries with available data, over $50 \%$ of people reported having discriminatory attitudes towards people living with HIV. One specific study conducted in Botswana, Sub-Saharan Africa, found that half of young children and one-fifth of older youth believed that if someone is known to have the HIV, they should be isolated even if they do not show signs of illness.

Stigmatization would make people hesitant to get the test done, therefore, more PLWHA are unaware that they are suffering from HIV/AIDS, and are thereby putting his/her sexual partners and/or needle sharers at risk of getting infected, due to lack of precautionary measures.

Study participants had some misconceptions relating to HIV acquisition and treatment. Among them is pseudo-immunity, which is a deeply rooted belief that Muslims practicing Islam would not get infected with HIV/AIDS.

Furthermore, during association analysis gender, age and monthly family income showed significant association when entered in both bivariate and multivariate analysis. This study agreed with another study done in Mangalore 2007 which showed almost the same association.

\section{Practices}

According to this study, only $26.3 \%$ of the respondents had good practice. The study has also shown that only 134 (22.9\%) of the respondents ever visited VCT centers while a very small number of participants $127(21.7 \%)$ had shown their compliance of preventive measures. This is lower than similar study conducted in South West Region of Cameroon which reported that 
$40.5 \%$ of the respondents had good practice. In contrast to this, a study done in Gonder, Ethiopia, showed that only $25 \%$ of students had poor practice.

Fortunately, Somali community is $100 \%$ Muslims who are expected to follow the Islamic values which forbid several behaviours that contribute to the transmission of HIV including intoxication, premarital and extramarital sex. The high valuation of premarital abstinence and marital fidelity are examples of how Muslim values can result in reducing HIV risk behaviours. However, the modes of HIV transmission are more than these.

\section{Conclusion}

\section{CONCLUSION AND RECOMMENDATION}

Good knowledge, favourable attitude and better practices are very useful tools prior to any intervention to assess the extent to which individuals or communities are ready to adopt riskfree behaviors. In this study, $70.0 \%, 50.8 \%$ and $26.3 \%$ of participants had a good knowledge, favourable attitude and better practices of HIV/AIDS.

With regard to Knowledge and attitude levels, the gender, age, level of education, occupation and monthly family income showed significant association. However, no association was found in terms of practice.

\section{Recommendation}

1. There is a need for developing policies and strategies to raise community awareness about HIV/AIDS in order to decrease the risk of contracting HIV infection.

2. Targeted media and social marketing should be used to improve people's knowledge, attitude and practice towards HIV/AIDS and remove the existing misconceptions

3. There is a need to establish VCT centers which give free counseling and testing facilities.

4. There is a need for making HIV/AIDS related health services more client-friendly may lead to increased use of the facilities by the community.

5. There is a need for training peers, to be positive role models that positively influence people's behaviours

6. There is a need for community figures and religious leaders to involve in the fight against the disease.

7. Conducting further research on HIV specific areas (i.e. youth and sex specific)

\section{References}

Abdala N, Crowe M, Tolstov Y, Heimer R. Survival of human immunodeficiency virus type 1 after rinsing injection syringes with different cleaning solutions. Subst Use Misuse. 2004;39:581-600.

Aggleton P (2000) Comparative analysis : Research Studies From India and Uganda, HIV \& AIDS related Discrimination, Stigmatization and Deniel, Geneva, Switzerland. Busza J (1999) Literature Review: C.

Ahmed HJ et al (1991). Syphilis and human immunodeficiency virus seroconversion during a six month follow-up of female prostitutes in Mogadishu, Somalia. International Journal of STD and AIDS, 1991, 2:119-123.

Berg CJ, Michelson SE, Safren SA. Behavioral aspects of HIV care: adherence, depression, substance use, and HIVtransmission behaviors. Infect Dis Clin North Am. 2007;21:181-200.

Campo J, Perea MA, del Romero J, Cano J, Hernando V, Bascones A. Oral transmission of HIV, reality or fiction? An update. Oral Dis. 2006;12(3):219-228.

Catania J.A et al (1990) Towards an understanding of risk behavior: An AIDS Risk Reduction Model (ARRM)

Health Education and Behaviour Quarterly 17,53-72.

Centers for Disease Control and Prevention. Evolution of HIV/AIDS prevention programs--United States, 19812006. MMWR. 2006;55:597-603.

Centers for Disease Control and Prevention. The Global HIV/AIDS pandemic, 2006. MMWR. 2006;55:841-844. 
Dahie, H. A., \& Heyle, A. A. (2019). Knowledge, attitude, practices and their associated factors towards HIV/AIDS among residents of Benadir Region, Somalia. Advances in Social Sciences Research Journal, 6(1) 240-261.

Chaillon A, Gianella S, Wertheim JO, Richman DD, Mehta SR, Smith DM. HIV migration between blood and cerebrospinal fluid or semen over time. J Infect Dis. 2014;209(10):1642-1652.

Champenois K, Cousien A, Cuzin L, Le Vu S, Deuffic-Burban S, Lanoy E, Lacombe K, et al. Missed opportunities for HIV testing in newly-HIV-diagnosed patients, a cross sectional study. BMC Infect Dis. 2013 May 2;13:200. doi: 10.1186/1471-2334-13-200.

Cohen MS, Chen YQ, McCauley M, et al; HPTN 052 Study Team. Antiretroviral Therapy for the Prevention of HIV-1 Transmission. N Engl J Med. 2016;375(9):830-839.

Cohen MS, Chen YQ, McCauley M, et al; HPTN 052 Study Team. Antiretroviral Therapy for the Prevention of HIV-1 Transmission. N Engl J Med. 2016;375(9):830-839.

Cohen MS, Hellmann N, Levy JA, DeCock K, Lange J. The spread, treatment, and prevention of HIV-1: evolution of a global pandemic. J Clin Invest. 2008;118:1244-1254.

Dahie H.A and Heyle A.A (2018). HIV/AIDS related misconceptions. Unpublished manuscript.

De Cock KM, Jaffe HW, Curran JW. Reflections on 30 years of AIDS. Emerg Infect Dis. 2011;17(6):1044-1048.

De Cock KM, Jaffe HW, Curran JW. The evolving epidemiology of HIV/AIDS. AIDS. 2012;26:1205-1213.

DiClemente RJ, Crittenden CP, Rose E, Sales JM, Wingood GM, Crosby RA, Salazar LF. Psychosocial predictors of HIV-associated sexual behaviors and the efficacy of prevention interventions in adolescents at-risk for HIV infection: what works and what doesn't work? Psychosom Med. 2008;70:598-605.

Hanege FM, Kalcioglu MT, Sargin F, Cetinkaya Z, Tekin M, Vahaboglu H. Does cerumen have a risk for transmission of HIV? Eur J Clin Microbiol Infect Dis. 2015;34:789-793.

Holtgrave D. Evidence-based efforts to prevent HIV infection: an overview of current status and future challenges. Clin Infect Dis. 2007;45 Suppl 4:S293-299.

Johnson BT, Scott-Sheldon LA, Huedo-Medina TB, Carey MP. Interventions to reduce sexual risk for human immunodeficiency virus in adolescents: a meta-analysis of trials, 1985-2008. Arch Pediatr Adolesc Med. 2011;165:77-84.

Jukes M, Simmons S, Bundy D. Education and vulnerability: the role of schools in protecting young women and girls from HIV in southern Africa. AIDS. 2008;22 Suppl. 4:S41-56.

Kahn JO, Walker BD. Acute human immunodeficiency virus type I infection. $N$ Engl J Med. 1998;339:33-39.

Khalsa AM. Preventive counseling, screening, and therapy for the patient with newly diagnosed HIV infection. Am Fam Physician. 2006;73:271-280.

Khan H, Ishaq M, Khan H, Ishaq T (2008) Knowledge and attitude of students regarding HIV/AIDS in Peshawar University. Journal of the Pakistan Medical Association 33: 18-21.

Kidder DP, Wolitski RJ, Pals SL, Campsmith ML. Housing status and HIV risk behaviors among homeless and housed persons with HIV. J Acquir Immune Defic Syndr. 2008;49:451-455.

Kilmarx PH. Global epidemiology of HIV. Curr Opin HIV AIDS. 2009;4:240-246.

Klein PW, Martin IB, Quinlivan EB, Gay CL, Leone PA. Missed Opportunities for Concurrent HIV-STD Testing in an Academic Emergency Department. Public Health Rep. 2014;129 Suppl 1:12-20.

Krishnan S, Dunbar MS, Minnis AM, Medlin CA, Gerdts CE, Padian NS Poverty, gender inequities, and women's risk of human immunodeficiency virus/AIDS. Ann N Y Acad Sci. 2008;1136:101-110.

Lamptey PR. Reducing heterosexual transmission of HIV in poor countries. BMJ. 2002;324:207-211.

Maartens G, Celum C, Lewin SR. HIV infection: epidemiology, pathogenesis, treatment, and prevention. Lancet. 2014;384(9939):258-271.

Monterroso ER, Hamburger ME, Vlahov D, et al. Prevention of HIV infection in streerecruited injection drug users: the Collaborative Injection Drug User Study (CIDUS). J Acquir Immune Defic Syndr. 2000;25:63-70.

Neel C, Etienne L, Li Y, Takehisa J, Rudicell RS, Bass IN, Moudindo J, et al. Molecular epidemiology of simian immunodeficiency virus infection in wild-living gorillas. J Virol. 2010;84:1464-1476.

Nicolás D, Ambrosioni J, Paredes R, Marcos MÁ, Manzardo C, Moreno A, Miró JM. Infection with human retroviruses other than HIV-1: HIV-2, HTLV-1, HTLV-2, HTLV-3 and HTLV-4. Expert Rev Anti Infect Ther. 2015;13(8):947-963. 
Nyamweya S, Hegedus A, Jaye A, Rowland-Jones S, Flanagan KL, Macallan DC. Comparing HIV-1 and HIV-2 infection: Lessons for viral immunopathogenesis. Rev Med Virol. 2013;23:221-240.

Patel P, Borkowf CB, Brooks JT, Lasry A, Lansky A, Mermin J. Estimating per-act HIV transmission risk: a systematic review. AIDS. 2014;28(10):1509-1519.

Rouet F, Elenga N, Msellati P, Montcho C, Viho I, Sakarovitch C, Danel C, Rouzioux C, Leroy V, Dabis F. Primary HIV1 infection in African children infected through breastfeeding. AIDS. 2002;16:2303-2309.

Sayegh A, Rose S, Schapiro NA. Condom availability in middle schools: evidence and recommendations. J Pediatr Health Care. 2012;26(6):471-475.

Shepard RN, Schock J, Robertson K, et al. Quantitation of human immunodeficiency virus type 1 RNA in different biological compartments. J Clin Microbiol. 2000;38:1414-1418.

Smith HM (1986). AIDS. Lessons from history. MD. ;9:43-51.

UNAIDS (2008) Report on the global AIDS epidemic. Geneva: Joint United Nations programme on HIV/AIDS.

UNOCHA: (2005). Regions, districts and their populations: Somalia (Draft).

Visseaux B, Damond F, Matheron S, Descamps D, Charpentier C. Hiv-2 molecular epidemiology. Infect Genet Evol. 2016;46:233-240.

Yerly S, Hirschel B. Diagnosing acute HIV infection. Expert Rev Anti Infect Ther. 2012;10(1):31-41. 